\title{
Good reads for the
} materials researcher

I read constantly. It is part of who and what I am. Reading, whether fiction or nonfiction, is a pleasure and helps me in life and in my work. I hereby share with you some recent reads, recommending them to your attention. I understand that some of you will not like any of these books, but I hope that most of you find one or more interesting and useful.

The first book on my list is The New Science of Strong Materials (or Why You Don't Fall through the Floor) by J.E. Gordon. This is a classic, first published in 1968, which has been reprinted several times. The edition that I read is in paperback published by Princeton University Press in 2006, with an introduction by science writer Philip Ball. The book delves deeply into strength, cohesion, stress, and strain. It covers cracks, crack stopping, and dislocations. Chapters address composite materials, wood, ceramic, and metals. The book left me with a sense of wonder and a deep appreciation for research in this area that has improved all of our lives.

Next, I recommend the autobiography of Eric R. Kandel, who received the Nobel Prize in Physiology or Medicine in 2000 for his work on memory storage in the brain. His book is In Search of Memory (The Emergence of a New Science of the Mind). This technical autobiography covers details of his life as well as research during his lifetime into the phenomenology associated with memory storage and retrieval. These are areas in which I am profoundly ignorant, having overlooked them throughout my education. Nonetheless, I found the book readable and enjoyable. Kandel does an excellent job of juxtaposing his work with that of others in the field. The edition that I read was in paperback published by Norton in 2006.

Mark P. Silverman has written several highly interesting and readable books. I recommend A Universe of Atoms, An Atom in the Universe. The version that I read was in hardcover published in 2002 by Springer-Verlag. It is a revised version of And Yet It Moves published by Cambridge University Press in 1993. Although the book is a smorgasbord of strange and interesting physics, I was most highly interested in his discussions of interference effects using electrons.

Joe Jackson has written a marvelous book discussing historical events around the race to discover oxygen. The book, entitled $A$ World on Fire (A Heretic, an Aristocrat, and the Race to Discover Oxygen), follows the lives of Joseph Priestley (the heretic), Antoine Lavoisier (the aristocrat), and others during the time before, during, and after the French revolution. This era saw the rise and fall of the phlogiston theory and its replacement with one of the foundations of modern chemistry. The book highlights the tragic lives of both of the main protagonists in light of the revolutionary era in which they lived. I read a hardback version of the book published in 2005 by Viking.

Giancarlo Ghirardi has written an excellent book about the foundations of quantum theory. The book, entitled Sneaking a Look at God's Cards (Unraveling the Mysteries of Quantum Mechanics), covers the issues raised by superposition, interference, and entanglement. Although he discusses the usual topics in vogue in quantum information, including quantum cryptography, quantum communication, and quantum computers, the meat of the book is the discussion of quantum theory and nonlocality. He highlights the disputes between Einstein and Bohr,

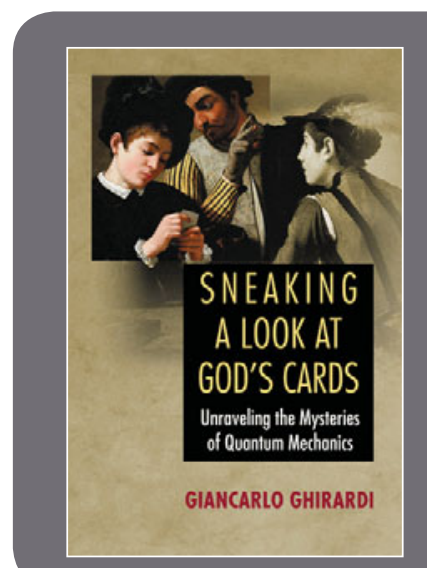
particularly related to the famous Einstein-Podolski-Rosen (EPR) paper and Bohr's response; and discusses hidden variables approaches to quantum theory, philosophical notions such as contextuality, many-worlds theories, and quantum histories. He concludes the book with a study of dynamic reduction efforts, including an approach developed by himself, Alberto Rimini, and Tullio Weber. The book is deep in content about the foundations of quantum theory, but should be accessible to those who have had a standard course in quantum mechanics and have knowledge of the Dirac notation of quantum states. The version of the book I read was in hardback published in English by Princeton University Press in 2004. The book was originally published in Italian under the title Un'occhiata alle carte de Dio (il Saggiatore, Milano, 1997).

I recommend any of the books written by Emil Wolf. I have several editions of Principles of Optics, the classic work by Born and Wolf, and have used it to my advantage throughout my

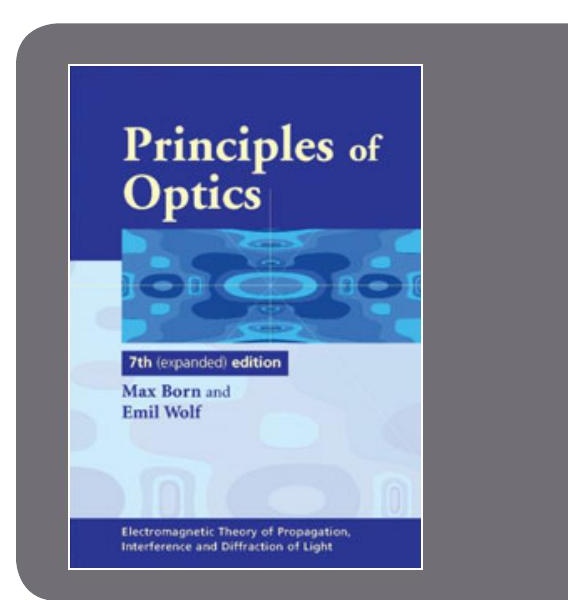


career. I recently read Professor Wolf's book Introduction to the Theory of Coherence and Polarization of Light. The version that I read is a hardback published by Cambridge University Press in 2007. He treats both spatial and temporal coherence, second-order and higher order coherence effects, phenomena produced by multiple sources with differing states of coherence, coherence effects on polarization, scattering, and a unified treatment of polarization and coherence. The book will be useful to those with a general interest in optics, to astronomers, and to materials scientists who deal with scattering, coherence, and polarization of electromagnetic fields.

All of my career, I have been fascinated by elementary particle physics and the giant machines used by high-energy researchers to understand elementary particles. Sometime ago Michael Riordan wrote a history of the work to establish the quark theory, entitled The Hunting of the Quark (A True Story of Modern Physics). The work sets the research in place with the personalities involved, from Murray Gell-Mann, Richard Feynman, Geoffrey Chew, Shoichi Sakata, George Zweig, Sheldon Glashow, Abdus Salam, Steven Weinberg, and a host of others. If you have ever wondered about the eightfold way, bootstrapping, S-matrix theory, partons, and quarks, this is a highly readable history. The version that I read was a paperback published by Touchstone/Simon and Schuster in 1987.

Nancy Thorndike Greenspan has written an excellent biography of Max Born entitled The End of the Certain World (The Life and Science of Max Born). The biography covers both personal and intellectual aspects of Born's life and work. The book covers much of Born's work, but highlights his work on quantum mechanics. His relationships with Albert Einstein, Neils Bohr, Fritz Haber, Werner Heisenberg, Wolfgang Pauli, P.A.M. Dirac, Max Planck, Pascual Jordan, and others are discussed in detail. The backdrop of the rise to power of Nazism and its impact on Born and others is addressed in detail. The book is highly readable. The version that I read was a hardback published by Basic Books in 2005 .

Dietrich Stoltzenberg has written an excellent biography of Fritz Haber entitled Fritz Haber (Chemist, Nobel Laureate, German, Jew). This book covers both personal and intellectual aspects of Haber's life and work, highlighting significant areas such as the Haber-Bosch process (synthesis of ammonia, nitrogen fixation) and the Born-Haber cycle (calculation of lattice energies, the energy required to form a crystal from its ions). Haber's relations with many of the chemists and physicists of that era are discussed in detail, including Albert Einstein, Max Born, Rudolf Stern, Richard Willstatter, Carl Bosch, Carl
Engler, James Franck, Walther Nernst, and Max Planck. The book discusses Haber's industrial affiliations, his academic work and affiliations, his Nobel Prize received in 1920, his participation in the first World War, and his exile from Germany after the ascension of the Nazi Party. Haber's life story is filled with intellectual triumph and personal tragedy. The version of the book that I read was a hardback published in 2004 by the Chemical Heritage Press.

For an introduction to special relativity, I highly recommend N. David Mermin's book It's About Time (Understanding Einstein's Relativity). The version that I read is a hardback published in 2005 by Princeton University Press. It covers the usual paradoxes, moving clocks, synchronization of clocks, space-time geometry, and $\mathrm{E}=\mathrm{mc}^{2}$. It is highly readable.

Michael F. Barnsley has written an excellent book entitled SuperFractals (Patterns of Nature). The version that I read was in hardback published by Cambridge University Press in 2006. The book follows on previous work in iterated function systems to introduce new ideas such as super iterated function systems and fractal tops. The book requires knowledge of at least some calculus and may be truly accessible only to those with more mathematical background. Nonetheless, the graphics are spectacular and alone worth the price of the book. The connections to real figures found in nature

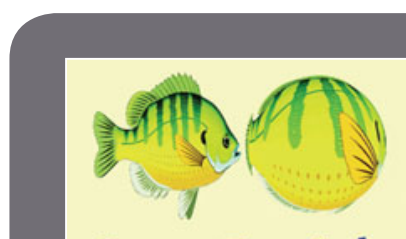

SuperFractals MICHAEL F. BARNSLEY

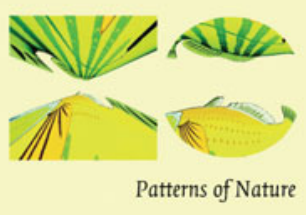
is amazing.

So many of my colleagues have acquired an interest in the programming language called Scientific Python that I recently determined to learn to program in this language. Consequently, I am working my way through several books to help: Beginning Python (From Novice to Professional) by Magnus Lie Hetland (Apress, 2008), Python Algorithms (Mastering Basic Algorithms in the Python Language) by Magnus Lie Hetland (Apress, 2010), and A Primer on Scientific Programming with Python by Hans Petter Langtangen (Springer, 2009). Although the books are available in paper, I am reading them on my iPad using the Kindle app.

Lest you believe that I am invested only in technical books, I also have some recommendations in fiction. For my friends at MRS Headquarters in Pittsburgh, I recommend the fantasy series by Wen Spencer including Tinker, Wolf Who Rules, Elfhome, and others in which a significant part of Pittsburgh has been transported to be a part of a planet filled with elves. If you are interested in adventure and mystery, I recommend the Jack Reacher novels by Lee Childs, the novels of Dick Francis, and the Spenser novels of Robert B. Parker.

Steve Moss 